CASE REPORT

\title{
Sclerochoroidal calcification associated with Gitelman syndrome and calcium pyrophosphate dihydrate deposition
}

\author{
R Gupta, V Hu, T Reynolds, R Harrison
}

J Clin Pathol 2005;58:1334-1335. doi: 10.1136/jcp.2005.027300

Sclerochoroidal calcification is an uncommon condition. Metabolic evaluation and clinical examination are important to exclude associated systemic conditions such as the Bartter and Gitelman syndromes. It has been suggested that the lesions seen in sclerochoroidal calcification are calcium pyrophosphate dihydrate crystals. This report describes the first documented case in the UK of sclerochoroidal calcification associated with Gitelman syndrome and calcium pyrophosphate dihydrate deposition.

$\mathrm{S}$ clerochoroidal calcification is a rare condition that can be metastatic or dystrophic, but is most often idiopathic The term idiopathic sclerochoroidal calcification is applied to those cases in which calcium phosphorous metabolism is normal. Metabolic evaluation and clinical examination is important to exclude associated conditions such as the Bartter and Gitelman syndromes. Fundal lesions can clinically simulate choroidal osteoma, melanoma, lymphoma, metastasis, choroiditis, and amelanotic choroidal naevus. ${ }^{12}$ Sclerochoroidal calcification is usually a bilateral condition seen in older (median age, 70 years) asymptomatic patients and the typical location is the post equatorial and superotemporal retina. ${ }^{1}$ To the best of our knowledge, this is the first documented case in the UK of sclerochoroidal calcification associated with Gitelman syndrome and calcium pyrophosphate dihydrate (CPPD) deposition.

\section{CASE REPORT}

After an annual optometric examination a 49 year old woman with no ocular symptoms was referred with bilateral fundal abnormalities. There was no previous documentation of the fundal lesions. An initial systemic enquiry was unremarkable and she took no ocular or systemic medication. Best corrected visual acuity was 6/6 (right eye) and 6/9 (left eye). Intraocular pressure was $16 \mathrm{~mm} \mathrm{Hg}$ bilaterally. Anterior segment examination was unremarkable. Fundoscopy showed numerous discrete yellow/white, slightly elevated lesions of the subretinal pigment epithelium (RPE) located around the superior temporal arcade bilaterally (fig 1). Some depigmentation of the RPE overlying the lesions was also noted. Fluorescein angiography showed non-specific changes with RPE atrophy. B scan ultrasound (fig 2) showed that the lesions were highly echogenic with acoustic shadowing.

Blood results revealed hypokalaemia $(3.1 \mathrm{mmol} / \mathrm{litre}$; normal range, 3.5-5.0), hypomagnesaemia (0.30 mmol/litre; normal range, 0.7-1.0), and raised globulin (39 g/litre; normal range, 18-35). Serum electrolytes-sodium, chloride, calcium, and phosphate-were normal, as was her parathyroid hormone value. A 24 hour urine analysis showed hyperkaliuria (102 mmol/24 hours; normal range, 25-100), hypocalciuria ( $1.6 \mathrm{mmol} / 24$ hours; normal range, $2.5-7.5$ ), natriuresis ( $227 \mathrm{mmol} / 24$ hours; normal range, 50-200), and

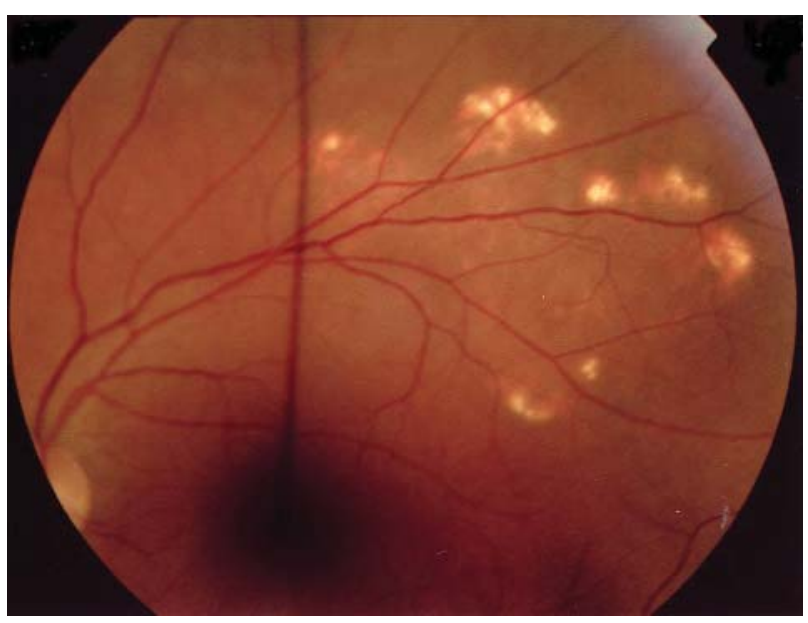

Figure 1 Colour fundus photographs of the left eye showing multiple yellow white lesions in the superotemporal retina. The right eye had a similar appearance. The linear artefact is secondary to focusing rod.

normal urine magnesium excretion $(4.18 \mathrm{mmol} / 24$ hours; normal range, 3.0-5.0). Blood $\mathrm{pH}$ was 7.529 confirming a metabolic alkalosis.

On further direct questioning, the patient described symptoms consistent with pseudogout and plain radiographs revealed extensive CPPD deposition in the fibrocartilage of the knee (fig 3) and in the hyaline cartilages of the shoulder, ankle, and elbow joints. A diagnosis of sclerochoroidal calcification secondary to Gitelman syndrome was made.

\section{DISCUSSION}

Idiopathic sclerochoroidal calcification requires no treatment, but screening tests for calcium phosphorous metabolism should be performed to exclude an underlying systemic disorder. ${ }^{12}$ Biochemically, Gitelman syndrome and Bartterlike syndromes are characterised by hypokalaemia associated metabolic alkalosis and normotension. Low serum magnesium is occasionally found in patients with Bartter syndrome, so that Gitelman syndrome, in which all patients have hypomagnesaemia, needs to be excluded. Differentiation is achieved by measuring urine calcium. In Gitelman syndrome, hypocalciuria is noted usually in the presence of a normal total serum calcium and ionised calcium, whereas in Bartter syndrome normal or high urine calcium excretion is seen. ${ }^{34}$ Our patient had a biochemical profile consistent with a diagnosis of Gitelman syndrome; namely, metabolic hypokalaemia alkalosis in the presence of hypomagnesaemia and hypocalciuria. This renal salt wasting disorder is an autosomal recessive condition caused by a defect in the thiazide

Abbreviations: CPPD, calcium pyrophosphate dihydrate; RPE, subretinal pigment epithelium 


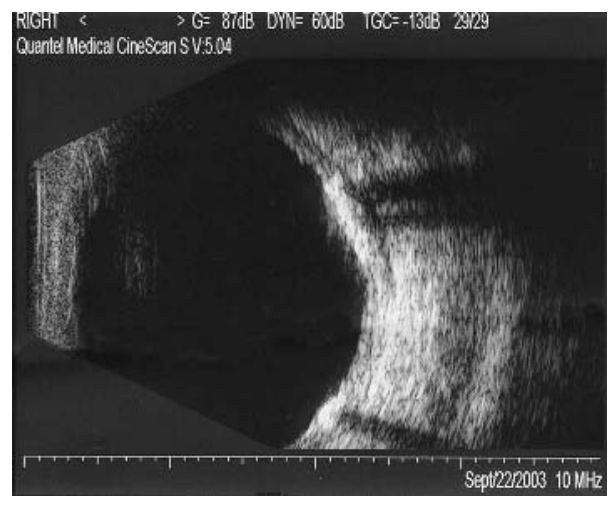

Figure 2 B scan ultrasound of the right eye showing multiple echogenic areas with acoustic shadowing.

sensitive $\mathrm{Na}-\mathrm{Cl}$ cotransporter in the distal convoluted tubule. ${ }^{5}$ It is often diagnosed in asymptomatic adults who present with unexplained hypokalaemia. However, these patients can be at risk of cardiac arrhythmias ${ }^{6}$ and other systemic symptoms ${ }^{1}$ as a result of the metabolic disturbance. On suspecting sclerochoroidal calcification, it is important to test for associated conditions, such as the Bartter and Gitelman syndromes, because both conditions can now be treated, ${ }^{17}$ the latter with oral magnesium pyrrolidone carboxylate.

"On suspecting sclerochoroidal calcification, it is important to test for associated conditions, such as the Bartter and Gitelman syndromes, because both conditions can now be treated"

Chondrocalcinosis has been suggested as a feature of Gitelman syndrome. ${ }^{158}$ Excess extracellular inorganic pyrophosphate has been recognised as a probable cause of CPPD crystal deposition disease. In patients with hypophophastasia, a deficiency of tissue non-specific alkaline phosphatase allows an increase in extracellular inorganic pyrophosphate and thus CPPD disease. ${ }^{9}$ Magnesium is a cofactor for alkaline phosphatase and hypomagnesaemia associated with Gitelman syndrome may thus theoretically reduce the activity of alkaline phosphatase and predispose to CPPD disease. ${ }^{8}$ It has been suggested that the lesions seen in sclerochoroidal calcification are CPPD crystals, ${ }^{10}{ }^{11}$ and recently a familial case of sclerochoroidal calcification and chondrocalcinosis ${ }^{12}$ has been reported. Our case further suggests that the sclerochoroidal lesions seen in Gitelman syndrome may be crystal deposits of CPPD and that the possible underlying molecular mechanism is secondary to hypomagnesaemia.

\section{Authors' affiliations}

R Gupta, Birmingham and Midland Eye Centre, City Hospital NHS Trust, Dudley Road, Birmingham B18 7QU, UK

V Hu, T Reynolds, R Harrison, Queens Hospital, Belvedere Road, Burton upon Trent, Staffordshire, DE13 ORB, UK

Correspondence to: Mr R Gupta, Birmingham and Midland Eye Centre, City Hospital NHS Trust, Dudley Road, Birmingham B1 8 7QU, UK; rajen.gupta1@btinternet.com

Accepted for publication 22 March 2005

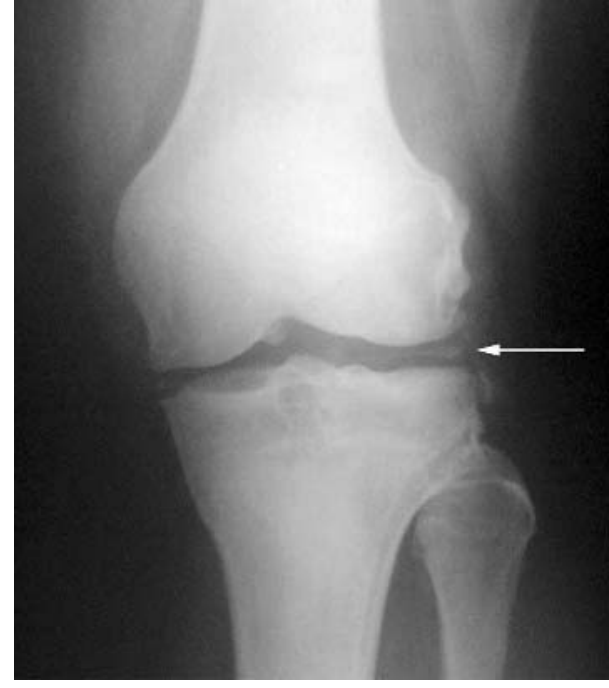

Figure 3 Plain $x$ ray showing calcium pyrophosphate deposition in the fibrocartilage of the left knee (white arrow).

\section{Take home messages}

- We report the first documented case in the UK of sclerochoroidal calcification associated with Gitelman syndrome and calcium pyrophosphate dihydrate deposition

- When investigating sclerochoroidal calcification, metabolic evaluation and clinical examination are important to exclude associated systemic conditions, such as the Bartter and Gitelman syndromes

\section{REFERENCES}

1 Honavar SG, Shields CL, Demirci H, et al. Sclerochoroidal calcification: clinical manifestations and systemic associations. Arch Ophthalmol $2001 ; 119: 833-40$.

2 Sivalingam A, Shields CL, Shields JA, et al. Idiopathic sclerochoroidal calcification. Ophthalmology 1991;98:720-4.

3 Rodriguez-Soriano J. Bartter and related syndromes: the puzzle is almost solved. Pediatr Nephrol 1998;12:315-27.

4 Naesens M, Steels P, Verberckmoes R, et al. Bartter's and Gitelman's syndromes: from gene to clinic. Nephron Physiol 2004;96:65-78.

5 Monnens L, Bindels R, Grunfeld JP. Gitelman syndrome comes of age. Nephrol Dial Transplant 1998;13:1617-19.

6 Bettinelli A, Tosetto C, Colussi G, et al. Electrocardiogram with prolonged QT interval in Gitelman disease. Kidney Int 2002;62:580-4.

7 Shields JA, Shields CL. CME review: sclerochoroidal calcification: the 2001 Harold Gifford lecture. Retina 2002;22:251-61.

8 Calo L, Punzi L, Semplicini A. Hypomagnesemia and chondrocalcinosis in Bartter's and Gitelman's syndrome: review of the pathogenetic mechanisms. Am J Nephrol 2000;20:347-50.

9 Ea HK, Liote F. Calcium pyrophosphate dihydrate and basic calcium phosphate crystal-induced arthropathies: update on pathogenesis, clinical features, and therapy. Curr Rheumatol Rep 2004;6:221-7.

10 Bourcier T, Blain P, Massin P, et al. Sclerochoroidal calcification associated with Gitelman syndrome. Am J Ophthalmol 1999;128:767-8.

11 Shields JA. Sclerochoroidal calcification in calcium pyrophosphate dihydrate deposition disease (pseudogout). Arch Ophthalmol 1997; 115:1077-9.

12 Boutboul S, Bourcier T, Heligon JP, et al. Familial pseudotumoral sclerochoroidal calcification associated with chondrocalcinosis. Br J Ophthalmol 2004;88:1094-5. 